\title{
A LEI 8.213/91 E O COMBATE AO ESTIGMA E À DISCRIMINAÇÃO DO TRABALHADOR ACIDENTADO
}

\section{LAW 8.213/91 AND COMBATING THE STIGMA AND DISCRIMINATION OF THE INJURED WORKER}

\author{
Mara Vidigal Darcanchy ${ }^{1}$ \\ Eduardo Milléo Baracat ${ }^{2}$
}

Luiza Novaki ${ }^{3}$

\section{RESUMO}

O presente artigo analisa a existência de estigma do trabalhador acidentado que possa desencadear a prática de atos discriminatórios em função das consequências do infortúnio laboral. Ainda, investiga-se em que medida a Lei $n^{\circ}$ 8.213/1991, que dispõe sobre os planos de Benefícios da Previdência Social, é eficaz no combate à discriminação do trabalhador acidentado. A referida norma, prevê a concessão de cotas em empresas e garantia de emprego para aqueles que sofrem acidente de trabalho, atuando como ação afirmativa em consonância com as normas de proteção à saúde do trabalhador, buscando reinserir a vítima de infortunísticas laborais no mercado de trabalho. A presente pesquisa adota o método dedutivo dialético, passando do estudo de conceitos mais amplos como o de acidente de trabalho, estigma

\footnotetext{
${ }^{1}$ Doutora e Mestre em Direito das Relações Sociais pela Pontifícia Universidade Católica de São Paulo (PUC/SP). Realizou estágio Pós-Doutoral em Direito Internacional (UniPg/IT). Especialista em Didática do Ensino Superior; em Metodologia da Pesquisa e; em Direito do Trabalho (USP); Graduação em Direito e Licenciatura em Letras português/inglês, com proficiência em espanhol, italiano e latim. Atualmente é Professora Pesquisadora e PNPDCAPES do Programa de Doutorado e Mestrado em Direito Empresarial e Cidadania do Centro Universitário Curitiba UNICURITIBA; Membro da Comissão Consultiva da OIT e Gerente voluntária de Projetos da ONU Mulheres/Meninas.

${ }^{2}$ Doutor em Direito das Relações Sociais pela Universidade Federal do Paraná (2002). Mestre em Direito Privado pela Universidade Federal do Paraná (1995). Diplôme Supérieur de 1'Université - Droit du Travail \& Sécurité Sociale pela Université Panthéon-Assas/Paris II (1998). Juiz Titular da 9a Vara do Trabalho de Curitiba. Professor Permanente do Programa de Mestrado em Direito Empresarial e Cidadania do UNICURITIBA. Realizou estágio Pós-Doutoral na Universidade de Coimbra (2016-2017).

${ }^{3}$ Graduada em Direito pelo Centro Universitário Curitiba - UNICURITIBA. Pós-Graduanda em Direitos e Processos do Trabalho e Previdenciário pela Academia Brasileira de Direito Constitucional - ABDConst.
} 
e discriminação, até que se torne possível compreender a eficácia da ordem jurídica no combate ao estigma e a discriminação do trabalhador acidentado.

Palavras-chave: Acidente de Trabalho, Estigma, Discriminação, Lei 8.213/91.

\begin{abstract}
The present paper refers to the analysis of the existence of stigma of the injured worker that could trigger the practice of discriminatory acts in function of the consequences of this labor misfortune. Also, it investigates in what extent Law number 8,213 of July 24, 1991, that dispose on the Plans of Benefits of Social Security, is effective combating the discrimination of the injured worker. This norm, provides for the granting of quotas in companies and guarantee of employment for those who suffer an accident at work, acting as affirmative action, in accordance with the norms of protection to the health of the worker, seeking to reinsert the victim of labor misfortunes in the market of job. The present research adopts the dialectical deductive method, going from the study of broader concepts such as work accidents, stigma and discrimination, until it becomes possible to understand to what extent Law 8.213/91 is effective in combating stigma and discrimination of the injured worker.
\end{abstract}

Key-words: Work Accident, Stigma, Discrimination, Law 8.213/91.

\title{
1. INTRODUÇÃO
}

O rompimento da barragem de Brumadinho, no início de 2019, resultou no maior acidente de trabalho já registrado no Brasil ${ }^{4}$ fazendo com que, devido à falta de uma cultura de prevenção, 270 pessoas se tornassem vítimas fatais do acidente, sendo que dentre estas, onze nunca foram encontradas.

Um ano após a ocorrência da referida fatalidade, a empresa Vale já recuperou seu valor de mercado. Enquanto isso, as tentativas de negociações entre o Ministério Público do Trabalho

\footnotetext{
${ }^{4}$ UOL NOTÍCIAS. Brumadinho é maior acidente de trabalho já registrado no Brasil. Disponível em: $<$ https://noticias.uol.com.br/ultimas-noticias/bbc/2019/01/28/brumadinho-pode-ser-2-maior-desastre-industrialdo-seculo-e-maior-acidente-de-trabalho-do-brasil.html>. Acesso em: 01/03/2019.
} 
de Minas Gerais e as famílias dos trabalhadores vítimas do acidente, ainda não estão finalizadas ${ }^{5}$.

Atualmente, de acordo com a Organização Internacional do Trabalho ${ }^{6}$, a cada 15 segundos, 160 trabalhadores são vítimas de acidentes relacionados ao trabalho.

Segundo o anuário estatístico da Previdência Social ${ }^{7}$, em 2014 mais de 700 mil trabalhadores foram vítimas de acidente de trabalho no Brasil. Embora esta quantia tenha sido reduzida nos anos seguintes, chegando a 576.951 trabalhadores acidentados no Brasil em 2018, deve-se atentar ao fato de que inúmeros trabalhadores se encontram em situação de informalidade. Deste modo, embora as estatísticas indiquem números alarmantes de trabalhadores vítimas de infortúnios laborais, ainda não refletem a realidade social brasileira.

Nesse contexto, o presente estudo é de extrema relevância, visto que busca verificar se o trabalhador acidentado carrega estigma que possa desencadear a prática de atos discriminatórios no ambiente de trabalho, que seriam de gravidade imensurável por serem ocasionados justamente em consequência da atividade laboral.

A partir dessa perspectiva, pretende-se analisar em que medida a Lei $n^{\circ} 8.213 / 1991$ é eficaz para combater a prática de tais atos, ao prever tanto a concessão de cotas em empresas com mais de cem empregados, quanto a garantia de emprego, para aqueles que sofrem acidente de trabalho.

Para o desenvolvimento da presente pesquisa, será utilizado o método dedutivodialético, passando de conceitos mais amplos para os mais restritos.

Buscar-se-á em primeira análise compreender o conceito e a classificação de acidente de trabalho no ordenamento jurídico brasileiro. Posteriormente, pretende-se explicar a diferença entre os conceitos de discriminação e estigma, para que seja possível verificar se o trabalhador acidentado possui estigma que possa desencadear a prática de atos discriminatórios.

Em último plano, serão apontados os dispositivos da Lei ${ }^{\circ}$ 8.213/91 que preveem cotas e estabilidade para o trabalhador acidentado, para que seja possível verificar se tais dispositivos são eficazes no combate à discriminação decorrente do infortúnio laboral.

\footnotetext{
${ }^{5}$ BBC NEWS BRASIL. "Estamos presos naquele dia": 1 ano após rompimento de barragem em Brumadinho, os impactos duradouros da tragédia. Disponível em: < https://www.bbc.com/ portuguese/geral51228582>. Acesso em: 28/03/2020.

${ }^{6}$ BRASIL. Tribunal Superior do Trabalho. Programa Nacional de Prevenção de Acidentes de Trabalho: Acidentes de Trabalho no mundo. Disponível em: <http://www.tst.jus.br/web/trabalho seguro/acidentes-detrabalho-no-mundo>. Acesso em: 28/03/2020.

${ }^{7}$ BRASIL. Ministério da Economia. Secretaria de previdência. Anuário Estatístico de Acidente do Trabalho. Disponível em <http://www.previdencia.gov.br/dados-abertos/dados-abertos-sst/>. Acesso em: 28/03/2020.
} 


\section{ACIDENTE DO TRABALHO: CONCEITO E CLASSIFICAÇÃO}

A Revolução Industrial que eclodiu no século XVIII foi marcada pelo grande avanço tecnológico gerado em decorrência de invenções mecânicas como a máquina de fiar, o tear hidráulico e o tear mecânico (VICENTINO, 2010, p.398), que aumentaram a produção das grandes indústrias, fazendo com que muitas pessoas que viviam no campo, migrassem para as cidades e passassem a exercer atividades notoriamente explorada nas fábricas.

Com o objetivo de alcançar a produção em série que gerasse maior resultados econômicos, o número de acidentes de trabalho teve aumento significativo, tanto em decorrência da ausência de preparo dos trabalhadores para utilização das máquinas, quanto pela elevada jornada de trabalho. A partir disso, "verificava-se que o acidentado no trabalho não conseguia nova colocação em outras empresas, ficando totalmente desprotegido" (MARTINS, 2005, p.414).

Nesse contexto, os reflexos sociais decorrentes do grande número de acidente de trabalho, indicaram a necessidade da criação de normas específicas destinadas a proteção da saúde do trabalhador e ao amparo econômico do mesmo, bem como de seus dependentes, perante a ocorrência de infortúnios laborais.

Atualmente, as normas brasileiras aplicáveis ao trabalhador acidentado estão previstas na Lei $n^{\circ} 8.213 / 1991$, que define o acidente de trabalho como aquele que ocorre pelo exercício do trabalho a serviço de empresa, pelo empregado doméstico ou segurado especial, provocando lesão corporal ou perturbação funcional que ocasiona a morte, perda ou redução, seja permanente ou temporária, da capacidade para o trabalho ${ }^{8}$.

Ainda, a lei ainda menciona que serão equiparados ao acidente de trabalho, as doenças ocupacionais, as concausas e outras hipóteses específicas nela previstas.

As doenças ocupacionais se subdividem em doença profissional e doença do trabalho. Ao contrário do acidente de trabalho propriamente dito, se manifestam de maneira interna podendo se relacionar a diversos e imprevisíveis fatores e se agravar ao longo do tempo.

A doença profissional é aquela desencadeada exclusivamente pelo exercício de determinada atividade, ou seja, é própria de determina profissão, motivo pelo qual tem nexo causal presumido com o labor desenvolvido ${ }^{9}$. A doença do trabalho, por sua vez, não guarda

\footnotetext{
${ }^{8}$ BRASIL. Lei $\mathbf{n}^{\mathbf{0}}$ 8.213, de 24 de julho de 1991. Dispõe sobre os Planos de Benefícios da Previdência Social e dá outras providências. Disponível em <http://www.planaltogov.br/ccivil_03/LEIS/ L8213cons.htm> Acesso em: 28/03/2020. art.19.

${ }^{9}$ BRASIL. Decreto no 3.048, de 06 de maio de 1999. Aprova o Regulamento da Previdência Social, e dá outras providências. Diário Oficial da União, Brasília, DF, 07 de maio de 1999. Art. 337, §3º.
} 
relação direta e presumida com a atividade laboral. Apesar disso, é diretamente relacionada a ela, uma vez que, embora seja uma doença comum, é adquirida devido a condições especiais em que o trabalho é desenvolvido (OLIVEIRA, 2018, p. 53).

As concausas referem-se a hipóteses em que o acidente está ligado ao trabalho, que contribui direta ou indiretamente para a morte do empregado, para a perda ou redução de sua capacidade, mas não tem nele sua única causa. ${ }^{10}$ Estas não guardam relação necessária com o trabalho do acidentado (HORVATH, 2003, p. 231), podendo ser preexistentes, concomitantes ou supervenientes ao evento principal que deu origem ao acidente ou a doença ocupacional.

Destaca-se ainda, que a legislação também equiparava ao acidente de trabalho o denominado acidente de trajeto ou acidente in itinere, sendo assim considerado aquele ocorrido durante o deslocamento do empregado de sua residência para o local de trabalho ou vice-versa (OLIVEIRA, 2018, p. 62). ${ }^{11}$

Pertinente ressaltar ainda, que existem outras circunstâncias que o legislador optou por equiparar ao acidente de trabalho, como ocorre com o trabalhador que adquire doença proveniente de contaminação acidental no exercício da atividade ${ }^{12}$.

Ainda, considera-se acidente de trabalho aquele sofrido no horário e local de trabalho, em consequência de ato de agressão, sabotagem ou terrorismo; ofensa física intencional, por motivo de disputa relacionada ao trabalho; ato de imprudência, negligência ou imperícia de terceiro ou companheiro de trabalho; ato de pessoa privada do uso da razão; desabamento, inundação, incêndio e outros casos fortuitos ou decorrentes de força maior no ambiente e no local de trabalho. ${ }^{13}$

É igualmente equiparado ao acidente de trabalho aquele sofrido, ainda que fora do local e horário de trabalho, na execução de ordem ou realização de serviço sob a autoridade da empresa; na prestação espontânea de qualquer serviço à empresa para lhe evitar prejuízo ou proporcionar proveito; em viagem a serviço da empresa, inclusive para estudo quando

\footnotetext{
${ }^{10}$ BRASIL. Lei $\mathbf{n}^{\mathbf{0}}$ 8.213, de 24 de julho de 1991. Dispõe sobre os Planos de Benefícios da Previdência Social e dá outras providências. Disponível em <http://www.planalto.gov.br/ccivil_03/ LEIS/L8213 cons.html>. Acesso em: 28/03/2020. Art. 21, I.

${ }^{11}$ Entretanto, com a promulgação da Medida Provisória no 905 de 11/11/2019, encontra-se, a princípio, revogado o artigo de lei referente a infortúnios ocorridos durante o percurso, o que, evidentemente, deve ser confirmado pelo Poder Legislativo, nos termos do art. 62, $\S 3^{\circ}$, da Constituição.

${ }^{12}$ BRASIL. Lei $\mathbf{n}^{\mathbf{0}}$ 8.213, de 24 de julho de 1991. Dispõe sobre os Planos de Benefícios da Previdência Social e dá outras providências. Disponível em <http://www.planalto.gov.br/ccivil_03/ LEIS/L8213cons.htm>. Acesso em: 28/03/2020. Art. 21, III.

${ }^{13}$ BRASIL. Lei $\mathbf{n}^{\circ}$ 8.213, de 24 de julho de 1991. Dispõe sobre os Planos de Benefícios da Previdência Social e dá outras providências. Disponível em <http://www.planalto.gov.br/ccivil_03/LEIS/L8213cons.htm>. Acesso em 28/03/2020. Art. 21, II.
} 
financiada por esta dentro de seus planos para melhor capacitação da mão-de-obra, independentemente do meio de locomoção utilizado, inclusive em veículo de propriedade do segurado. ${ }^{14}$

Ao longo da história, verificou-se que muitas vezes o trabalhador que sofria qualquer destas espécies de infortúnio laboral permanecia com sequelas, como cicatrizes e amputações, ou com enorme dificuldade para exercer outras atividades.

Tais situações passaram a fazer sombra sobre os acidentados no trabalho, tornando-os estigmatizados e fazendo com que eles permanecessem totalmente desprotegidos e apresentassem dificuldade para se inserir novamente no mercado de trabalho.

\section{O ESTIGMA E A DISCRIMINAÇÃO DO TRABALHADOR ACIDENTADO}

O termo estigma remete a ideia de uma marca, uma cicatriz perdurável ${ }^{15}$, e está relacionado a um atributo depreciativo, podendo ser entendido como a "situação do indivíduo que está inabilitado para a aceitação social plena” (GOFFMAN, 2017, p. 11).

Este conceito considera que a sociedade define padrões de normalidade, assim, quando determinado indivíduo apresenta um atributo que não é considerado "normal" pela sociedade, ela possui um estigma. Por isso, pode-se concluir que os padrões sociais de normalidade criam duas classes diferentes de indivíduos, os considerados normais e os estigmatizados (GOFFMAN, 2017, p. 11).

Carlos Roberto Bacila (BACILA, 2015, p. 30) explica que o estigma possui duas dimensões diversas, sendo uma objetiva e outra subjetiva. O estigma objetivo é uma marca ou um sinal exterior do indivíduo, enquanto o estigma subjetivo é o significado negativo atribuído àquela marca (estigma objetivo).

Ocorre que, quando o sujeito considerado "normal" entra em contato com outro que possui estigma, tende a tratá-lo de modo diferenciado, podendo muitas vezes discriminá-lo, motivo pelo qual, não raramente, o sujeito estigmatizado opta por se afastar do convívio social, ampliando ainda mais a separação entre os "normais" e os "estigmatizados".

A conduta discriminatória é o ato de tratar alguém de maneira diferenciada, podendo ser positiva ou negativa (DELGADO, 2019, p. 951). A discriminação positiva é aquela em que se

\footnotetext{
${ }^{14}$ BRASIL. Lei no 8.213, de 24 de julho de 1991. Dispõe sobre os Planos de Benefícios da Previdência Social e dá outras providências. Disponível em <http://www.planalto.gov.br/ccivil_03/ LEIS/L8213cons.htm>. Acesso em 28/03/2020. Art. 21, IV.

15 DICIONÁRIO DO AURÉLIO. Disponível em: <https://dicionariodoaurelio.com/estigma〉. Acesso em 20/10/2018.
} 
concede tratamento diferenciado a alguém para que este possa usufruir de seus direitos. A discriminação denominada negativa, por sua vez, é aquela que suprime direitos (FACHIN, 2015, p. 281). É o que ocorre com a mulher em função do seu gênero, com o negro em função de sua cor, e também como o trabalhador acidentado.

Isso porque, conforme demonstrado anteriormente, o acidente de trabalho gera a perda ou redução da capacidade laboral, ainda que de forma temporária, de modo que ao retornar ao ambiente de trabalho, muitas vezes o empregado não pode exercer a mesma função ou a exerce com produtividade inferior a exercida antes do infortúnio laboral.

Essa limitação do empregado acidentado, que não desempenha suas funções habituais ou não as faz com a mesma habilidade, pode não ser bem vista pelo empregador em decorrência das imposições do sistema capitalista. Por este motivo, nota-se que o empregado que sofre acidente de trabalho torna-se um forte candidato a ser dispensado, com ou sem justa causa, na primeira oportunidade em que o empregador decide reduzir o número de empregados (LOPES, 2002, p. 267).

Embora a discriminação em face do trabalhador acidentado não suscite tantos debates quanto outras formas de discriminação, tais como a que ocorre em função do gênero ou cor, "é a forma de discriminação mais repudiada porque o empregado adquiriu a condição discriminatória em razão do próprio trabalho" (OLMOS, 2008, p. 90).

Quando o acidente de trabalho é conhecido, a vítima do infortúnio laboral passa a ser vista pelo empregador como um funcionário prejudicial economicamente, que pode vir a se ausentar de maneira frequente por razões médicas, ser novamente afastado em decorrência do retorno ou agravamento de uma doença ocupacional, ou ainda, que não será capaz de suprir as necessidades da empresa.

Por isso, o acidente de trabalho se torna um estigma, uma marca que acompanha o trabalhador acidentado por longo período, ou mesmo por tempo indeterminado, fazendo com que as demais pessoas o vejam como alguém diferente, que não é capaz de exercer as mesmas funções ou não tem os mesmos cuidados que um trabalhador considerado "normal".

Nesse contexto, com a finalidade de se alcançar a igualdade material dos trabalhadores acidentados em relação aos demais, a ordem jurídica prevê ações afirmativas, que consistem em "uma série de medidas e políticas sociais com o intuito de atenuar ou eliminar as desigualdades (discriminações) de determinados grupos sociais" (JORGE NETO; CAVALCANTE, 2018, p.120). 
Atualmente, o Brasil adota inúmeras modalidades de ações afirmativas, tais como as cotas de $50 \%$ em instituições federais para estudantes que cursaram o ensino médio em escola pública $^{16}$, e as cotas de $30 \%$ para cada sexo nos partidos políticos e coligações ${ }^{17}$.

São também exemplos de ações afirmativas, as cotas em empresas para reabilitados ou pessoas portadoras de deficiência e a garantia de emprego destinada ao trabalhador acidentado, ambas asseguradas pela Lei $\mathrm{n}^{\circ} 8.213 / 91^{18}$, das quais tratar-se-á a seguir.

\section{COTAS DESTINADAS A BENEFICIÁRIOS REABILITADOS OU PESSOAS COM DEFICIÊNCIA}

O artigo 93 da Lei $\mathrm{n}^{\circ} 8.213 / 91^{19}$ determina que a empresa que tiver 100 empregados ou mais é obrigada a destinar entre $2 \%$ e $5 \%$ de seus cargos a beneficiários reabilitados ou pessoas com deficiência, habilitadas.

Da leitura do referido dispositivo, extrai-se que as cotas em questão são destinadas a duas classes diversas, quais sejam, a de pessoas com deficiência que foram habilitadas e a de reabilitados.

A habilitação e a reabilitação são formas de Serviços Social, que buscam garantir ao beneficiário incapacitado para sua atividade laboral e às pessoas com deficiência, meios para a educação ou reeducação, adaptação ou readaptação profissional e social para que possam participar do mercado de trabalho (CASTRO, 2009, p. 677).

O programa de habilitação é destinado a pessoas inaptas para exercer qualquer atividade. Refere-se a pessoas que nunca estiveram plenamente capacitadas para determinada função, como é o caso da pessoa com deficiência que nunca prestou atividade para uma empresa em decorrência da sua condição.

\footnotetext{
${ }^{16}$ BRASIL, Lei ${ }^{0}$ 12.711, de 29 de Agosto de 2012. Dispõe sobre o ingresso nas universidades federais e nas instituições federais de ensino técnico de nível médio e dá outras providências. Diário Oficial da União. Brasília, 30/8/2012. Disponível em: 〈http://www.planalto.gov.br/CCIVIL_03/_Ato2011-2014/2012/Lei/L12711.htm〉. Acesso em: 28/03/2020. Art. $1^{\circ}$.

${ }^{17}$ BRASIL, Lei $\mathbf{n}^{\mathbf{0}}$ 9.504, de 30 de Setembro de 1997. Estabelece normas para as eleições. Diário Oficial da União. Brasília, 1/10/1997. Art. 10, §3 . Disponível em: <http://www.planalto.gov.br/ ccivil_03/leis/L9504.htm>. Acesso em: 28/03/2020.

${ }^{18}$ BRASIL, Lei $\mathbf{n}^{\mathbf{0}} \mathbf{8 . 2 1 3}$, de 24 de Julho de 1991. Dispõe sobre os Planos de Benefícios da Previdência Social e dá outras providências. Diário Oficial da União. Brasília, 25/077/1991. Disponível em: < http://www2.camara.leg.br/legin/fed/lei/1991/lei-8213-24-julho-1991-363650-publicacaooriginal-1-pl.html>. Acesso em: 28/03/2020.

${ }^{19}$ BRASIL, Lei $\mathbf{n}^{\mathbf{0}} \mathbf{8 . 2 1 3}$, de 24 de Julho de 1991. Dispõe sobre os Planos de Benefícios da Previdência Social e dá outras providências. Diário Oficial da União. Brasília, 25/077/1991. Disponível em: < http://www2.camara.leg.br/legin/fed/lei/1991/lei-8213-24-julho-1991-363650-publicacaooriginal-1-pl.html>. Acesso em: 28/03/2020. Art. 93.
} 
A reabilitação, por sua vez, destina-se aquele que já esteve apto para exercer determinada função, mas que por algum motivo determinado, veio a perder tal aptidão. É o que ocorre, por exemplo, com o segurado que sofre acidente de trabalho e precisa reaprender a exercer sua atividade.

Importante ressaltar que a reabilitação só cumpre com seu objetivo quando o indivíduo reabilitado participa de maneira efetiva na comunidade em que está inserido (CASTRO, 2009, p. 677), de modo que, o fim da reabilitação é a integração da pessoa nos meios sociais dos quais fazia parte. Assim, pode-se concluir que a reabilitação do empregado acidentado somente será efetiva quando ele estiver novamente inserido no mercado de trabalho, desempenhando sua função da forma como a fazia antes do infortúnio.

Com efeito, ao destinar percentual de vagas em empresas para os trabalhadores com deficiência habilitados e para os reabilitados, pretendeu-se permitir que tais grupos tenham oportunidade de ingressar no mercado de trabalho, reduzindo os efeitos de suas limitações, visto que, sem tal previsão legal, as chances de ingresso seriam reduzidas.

A reserva de cotas no ambiente de trabalho não constitui direito individual, mas sim direitos difusos daqueles que se inserem na proteção legal. Assim, caso a porcentagem mínima de vagas definida pela legislação não seja observada, a conduta da empresa é presumidamente discriminatória, podendo ser discutida por meio de ação civil pública.

A legislação prevê ainda que a dispensa de trabalhador reabilitado ou da pessoa com deficiência habilitada, ao final de contrato por prazo determinado de mais de noventa dias, e a dispensa imotivada, no contrato por prazo indeterminado, só poderá ocorrer após a contratação de substituto em condição semelhante ${ }^{20}$.

Assim, embora a legislação seja referente a direito difuso, o trabalhador que tiver seu contrato de trabalho rescindido e verificar que a empresa empregadora não contratou outro empregado em condição semelhante, poderá requerer sua reintegração devido a nulidade contratual em decorrência de violação à norma federal.

A lei prevê que incumbe ao Ministério do Trabalho e Emprego fiscalizar e gerar dados estatísticos sobre o total de empregados e as vagas preenchidas por pessoas com deficiência e por beneficiários reabilitados da Previdência Social, devendo fornecer tais informações aos

\footnotetext{
${ }^{20}$ BRASIL, Lei ${ }^{\mathbf{0}}$ 8.213, de 24 de Julho de 1991. Dispõe sobre os Planos de Benefícios da Previdência Social e dá outras providências. Diário Oficial da União. Brasília, 25/077/1991. Disponível em: < http://www2.camara.leg.br/legin/fed/lei/1991/lei-8213-24-julho-1991-363650-publicacaooriginal-1-pl.html>. Acesso em: 09/09/2018. Art. 93, § $1^{\circ}$.
} 
sindicatos, às entidades representativas e a qualquer cidadão interessado ${ }^{21}$. Entretanto, desde a extinção do Ministério do Trabalho, a referida fiscalização vem sendo feita pela Secretaria Especial de Previdência e Trabalho do Ministério da Economia, a qual realiza em média 10 mil fiscalizações por ano ${ }^{22}$.

Caso seja constatado que determinada empresa não destinou o percentual mínimo definido pela lei para trabalhadores considerados reabilitados ou deficientes habilitados, ficará sujeita a aplicação de multa a ser imposta pelos órgãos fiscalizatórios em valor definido legalmente. ${ }^{23}$

Nota-se que a intenção do dispositivo legal em análise é permitir o acesso de pessoas com deficiência habilitadas ou reabilitadas pelo INSS ao mercado de trabalho, buscando impedir atos discriminatórios do empregador e permitindo que tais trabalhadores tenham igualdade de oportunidade.

Contudo, a aplicação de tal norma deve observar o princípio constitucional da razoabilidade, para que não gere ônus excessivo as empresas. Isso porque, é perfeitamente possível que a empresa inicie processo seletivo específico para pessoas nas condições exigidas pela lei e não encontre número suficiente de trabalhadores para preencher as cotas.

Ao analisar tal problemática, a Subseção I Especializada em Dissídios Individuais ${ }^{24}$, já entendeu que quando restar comprovado que a empresa não cumpriu a exigência legal, mas

\footnotetext{
${ }^{21}$ BRASIL. Lei no 8.213, de 24 de julho de 1991. Dispõe sobre os Planos de Benefícios da Previdência Social e dá outras providências. Disponível em <http://www.planalto.gov.br/ccivil_03/ LEIS/L8213cons.htm>. Acesso em 28/03/2020. Art. 93, $\$ 2^{\circ}$.

${ }^{22}$ BRASIL. Ministério da Economia. Secretaria de previdência. Lei que regulamentou inserção de pessoas com deficiência no mercado de trabalho completa 28 anos. Disponível em <http://www. previdencia.gov.br/noticias/7185-lei-que-regulamentou-insercao -de-pessoas-com-deficiencia-no-mercado-detrabalho-completa-28-anos>. Acesso em 28/03/2020.

${ }^{23}$ BRASIL. Lei no 8.213, de 24 de julho de 1991. Dispõe sobre os Planos de Benefícios da Previdência Social e dá outras providências. Disponível em <http://www.planalto.gov.br/ccivil_03/ LEIS/L8213cons.htm>. Acesso em: 09/09/2018. Art. 133.

${ }^{24}$ 1. EMBARGOS DE DECLARAÇÃO. ERRO MATERIAL. ACOLHIMENTO. Havendo erro material no julgado, acolhem-se os Embargos de Declaração. Se a correção do vício constatado na decisão embargada implica atribuir efeito modificativo aos Embargos de Declaração, deve-se assim proceder, a fim de aperfeiçoar o julgado. Embargos de Declaração providos com efeito modificativo. 2. AÇÃO CIVIL PÚBLICA. VAGAS DESTINADAS A PESSOAS PORTADORAS DE DEFICIÊNCIA. PREENCHIMENTO. ART. 93 DA LEI 8.213/91. MULTA. INDENIZAÇÃO POR DANO MORAL COLETIVO. ABSOLVIÇÃO 2.1. Conquanto seja ônus da empregadora cumprir a exigência prevista no art. 93 da Lei 8.213/91, ela não pode ser responsabilizada pelo insucesso, quando comprovado que desenvolveu esforços para preencher a cota mínima, sendo indevida a multa, bem como a condenação no pagamento de indenização por dano moral coletivo. 2.2. A empresa com 100 ou mais empregados deverá preencher de $2 \%$ a $5 \%$ de seus cargos com "beneficiários reabilitados" ou com pessoas portadoras de deficiência. Entretanto, in casu, é descabida a condenação ao pagamento de multa e indenização por dano moral coletivo em face do não cumprimento da exigência prevista no art. 93 da Lei 8.213/91, uma vez que ficou comprovado que a empresa empreendeu esforços a fim de preencher o percentual legal de vagas. Recurso de Embargos de que se conhece e a que se dá provimento para totalmente improcedente os pedidos formulados na Ação Civil Pública. (BRASIL, Tribunal Superior do Trabalho, SDI-1 - ED - E - ED - RR - 65820089.2009.05.09.0670 - Embargante: American Glass Products do Brasil Ltda. Embargado: Ministério
} 
juntou esforços na busca por candidatos com deficiência habilitados, ou reabilitados do INSS, não deverá ser condenada ao pagamento de multa e indenização por dano moral coletivo. Apesar disso, mantem-se a obrigação da empresa de promover a admissão de pessoas com deficiência ou reabilitados no percentual exigido pela lei.

Com isso, conclui-se que apesar da excelente intenção do legislador, ao tentar impedir atos discriminatórios por parte do empregador, que muitas vezes pretende deixar o empregado submetido ao processo de habilitação ou reabilitação fora de seu quadro de empregados, por acreditar que ele irá gerar ônus a empresa, o dispositivo por si só não é suficiente.

A ideia de inclusão no mercado de trabalho significa que a empresa deve adaptar os seus cargos para receber os empregados na condição em que se encontram. Deste modo, não é plausível que a empresa alegue não ter contratado empregados com deficiência habilitados ou reabilitados em razão da ausência de função que pudessem ser desempenhadas por eles. Isso porque, é ilusório cogitar que uma empresa que conta com número mínimo de 100 empregados, não possui nenhum cargo que possa ser ocupado por empregados em tais condições.

Apesar disso, ao obrigar as empresas a contrataram percentual mínimo de empregados nestas condições, há grande risco de que elas o façam apenas para não terem que pagar multa imposta, e submetam o trabalhador a uma atividade para a qual não estão efetivamente preparados, podendo colocar sua saúde e integridade física em risco.

Assim, é necessário que o serviço da Seguridade, que promove a habilitação e reabilitação, seja efetivo para apenas permitir a reinserção do trabalhador no mercado de trabalho, quando sua aptidão for inequívoca.

Ainda, não é suficiente que as empresas sejam submetidas a fiscalização para saber se estão cumprindo com o percentual mínimo imposto pela lei, sendo necessário verificar, com a mesma seriedade, se o trabalhador que ingressou na empresa por meio de cotas está desempenhando atividade adequada para sua condição.

Especificamente com relação ao trabalhador que sofre acidente de trabalho, é preciso que ele seja reinserido em função para a qual está efetivamente preparado, para que não corra o risco de sofrer novo infortúnio laboral, ou para que sua doença ocupacional não seja reativada ou agravada fazendo com que ele, novamente, precise se afastar de sua atividade habitual.

Assim, para que as cotas sejam efetivas no combate à discriminação do trabalhador acidentado submetido ao serviço de reabilitação, é necessário exigir que tais trabalhadores 
ocupem as funções adequadas, sob pena estar sacrificando sua saúde, ao tentar alcançar a igualdade material nas relações empregatícias.

Finda a análise acerca das cotas para pessoas com deficiência habilitadas e para reabilitados, passa-se agora ao estudo da estabilidade acidentária prevista no artigo 118 da Lei $\mathrm{n}^{\circ} 8.213 / 1991$.

\section{ESTABILIDADE DECORRENTE DO ACIDENTE DE TRABALHO}

A Lei 8.213/91 prevêt $\hat{}^{25}$ que o segurado que sofreu acidente do trabalho tem garantida, pelo prazo mínimo de doze meses, a manutenção do seu contrato de trabalho na empresa, após a cessação do auxílio-doença acidentário, independentemente da percepção de auxílio-acidente.

A legislação determina que a estabilidade do empregado acidentado se inicia com a cessação do benefício previdenciário de auxílio-doença acidentário em função da alta médica do INSS. Para fazer jus a garantia provisória de emprego, é necessário cumprir com os seguintes requisitos: sofrer acidente de trabalho nos termos definidos pela lei e ter direito ao recebimento do benefício de auxílio-doença acidentário.

Assim, ainda que o segurado receba auxílio-doença comum ao invés de receber o auxílio-doença acidentário, é possível que este tenha direito a estabilidade provisória quando restar comprovado que sua incapacidade funcional, que gerou seu afastamento por período superior a 15 dias, apresenta nexo causal com a atividade desenvolvida.

Deve-se atentar ainda a possibilidade de o trabalhador que sofre infortúnio laboral vir a ser afastado recebendo o benefício de aposentadoria por invalidez de modo temporário. Nessa hipótese, seria equivocado se apegar a interpretação literal da norma, sob pena de retirar a estabilidade de um trabalhador que, em função do acidente sofrido, encontrava-se em situação mais grave, por isso recebeu aposentadoria por invalidez, do que outro, em situação menos gravosa, que recebeu somente o benefício de auxílio-doença acidentário (CASTRO, 2009, p. 566).

No mesmo sentido, baseando-se em interpretação literal da norma, seria possível compreender que o empregado aposentado que sofrer acidente de trabalho não teria direito a

\footnotetext{
${ }^{25}$ BRASIL, Lei no 8.213, de 24 de Julho de 1991. Dispõe sobre os Planos de Benefícios da Previdência Social e dá outras providências. Diário Oficial da União. Brasília, 25/077/1991. Disponível em: <http://www2.camara.leg.br/legin/fed/lei/1991/lei-8213-24-julho-1991-363650-publicacaooriginal-1-pl.html>. Acesso em: 28/03/2020. art. 118.
} 
garantia provisória de emprego, visto que, nos termos da lei, não tem direito a receber o benefício de auxílio-doença acidentário ${ }^{26}$.

A respeito de tal situação, a $2^{\mathrm{a}}$ Turma do Tribunal Superior do Trabalho ${ }^{27}$ já esclareceu que o empregado aposentado que sofre acidente de trabalho tem direito a estabilidade provisória, mesmo não podendo receber o benefício de auxílio-doença acidentário. Isso porque, a garantia de emprego assegurada pela legislação vigente, busca garantir a readaptação do trabalhador as funções que exercia antes do infortúnio, além de impedir que o empregador atue de forma discriminatória, encerrando o contrato em razão do acidente.

Com relação a doença ocupacional que se equipara ao acidente de trabalho, a Súmula 378 do TST $^{28}$ determina que mesmo que a doença do trabalho seja constatada após a despedida do empregado, este manterá sua garantia de emprego.

Nesse sentido já se posicionou a $3^{\mathrm{a}}$ Turma do Tribunal Regional do Trabalho da $18^{\mathrm{a}}$ Região $^{29}$, ao julgar Reclamatória de empregado que, após ter sido despedido sem justa causa,

${ }^{26}$ BRASIL, Lei no 8.213, de 24 de Julho de 1991. Dispõe sobre os Planos de Benefícios da Previdência Social e dá outras providências. Diário Oficial da União. Brasília, 25/077/1991. Disponível em: < http://www2.camara.leg.br/legin/fed/lei/1991/lei-8213-24-julho-1991-363650-publicacaooriginal-1-pl.html>. Acesso em: 04/11/2018. art.124.

27 "ESTABILIDADE PROVISÓRIA - ACIDENTE DE TRABALHO - EMPREGADO APOSENTADO. In casu, o percebimento do auxílio-doença acidentário não se verificou ante o óbice legal contido no artigo 124, inciso I, da Lei $\mathrm{n}^{\circ} 8.213 / 91$, que, salvo no caso de direito adquirido, veda o recebimento cumulado de aposentadoria com auxílio-doença, o que não afasta o direito à estabilidade decorrente do acidente de trabalho, tendo em vista o atual entendimento desta Corte, que, levando em consideração os princípios do Direito do Trabalho e a interpretação finalística ou teleológica da norma, vem mitigando a exigência de percepção do auxílio-doença acidentário para a concessão da estabilidade, o que se percebe da leitura do item II da Súmula/TST no 378, e o fato de que o empregado, no presente caso, atendia aos pressupostos para o recebimento do referido auxílio, ou seja, sofreu acidente de trabalho, ficando afastado do trabalho por prazo superior a 15 dias. Recurso de revista conhecido e provido." (BRASIL, Tribunal Superior do Trabalho, 2a Turma, RR 8544400-81.2003.5.04.0900, Recorrente: João Onildo Cardoso da Silva, Recorrido: MADEF S.A. - Indústria e Comércio, Relator Min.: Renato de Lacerda Paiva, Julgamento: 16/09/2009, Publicação: 09/10/2009, Disponível em: <www.tst.jus.br>. Acesso em 25/10/2018).

${ }^{28}$ BRASIL, Tribunal Superior do Trabalho. Súmula no 378. ESTABILIDADE PROVISÓRIA. ACIDENTE DO TRABALHO. ART. 118 DA LEI No 8.213/1991. (inserido item III) - Res. 185/2012, DEJT divulgado em 25, 26 e 27.09.2012. I - É constitucional o artigo 118 da Lei no 8213/1991 que assegura o direito à estabilidade provisória por período de 12 meses após a cessão do auxílio-doença ao empregado acidentado. (ex-OJ no 105 da SBDI-1 inserida em 01.10.1997); II - São pressupostos para a concessão da estabilidade o afastamento superior a 15 dias e a conseqüente percepção do auxílio-doença acidentário, salvo se constatada, após a despedida, doença profissional que guarde relação de causalidade com a execução do contrato de emprego. (primeira parte - ex-OJ $\mathrm{n}^{\mathrm{o}} 230$ da SBDI-1 - inserida em 20.06.2001); III - O empregado submetido a contrato de trabalho por tempo determinado goza da garantia provisória de emprego decorrente de acidente de trabalho prevista no art. 118 da Lei $\mathrm{n}^{\circ} \quad 8.213 / 91$ Disponível $\quad$ em: Sumulas_com_indice/Sumulas_Ind_351_400.html\#SUM-378>. Acesso em 25/10/2018.

29 - EMENTA: DOENÇA OCUPACIONAL. ESTABILIDADE PROVISÓRIA. AUSÊNCIA DE PERCEPÇÃO DE BENEFÍCIO PREVIDENCIÁRIO. IRRELEVÂNCIA. A ausência de recebimento de benefícios previdenciários não é obstáculo ao reconhecimento da estabilidade provisória, quando for constatada, após a despedida, "doença ocupacional que guarde relação de causalidade com a execução do contrato de emprego" (Súmula 378, II, do TST). Portanto, comprovada a existência de doença ocupacional que guarda nexo de causalidade com o trabalho, o autor faz jus à estabilidade provisória. Logo, mostrou-se acertada a decisão do juízo de $1^{\circ}$ grau que declarou a nulidade da dispensa e determinou a reintegração imediata do reclamante no emprego, 
submeteu-se a perícia médica que constatou a existência de doença ocupacional no momento da rescisão contratual.

De forma unânime, a Turma entendeu que a ausência de recebimento de benefício previdenciário no curso do contrato de trabalho não é obstáculo ao reconhecimento da estabilidade provisória, quando, após a despedida, for constatada doença ocupacional que apresente relação de causalidade com a atividade desenvolvida.

Pertinente ressaltar que a estabilidade que decorre do infortúnio laboral não é sinônimo de manter o empregado no mesmo local de trabalho e função exercida antes do acidente (CASTRO, 2009, p. 566). Isso porque, muitas vezes é necessário colocá-lo em função diversa em razão de sua condição atual, observando as regras de reabilitação profissional, de modo que, a estabilidade significa apenas que o empregado não poderá ter seu contrato rescindido sem justa causa.

Desta forma, perante a violação de sua garantia de emprego, o trabalhador acidentado, poderá requerer sua reintegração pelo período faltante, sem excluir a possibilidade de compensação por eventuais danos materiais e morais sofridos.

A Súmula 396 do Tribunal Superior do Trabalho ${ }^{30}$ determina de forma clara que, após ter se encerrado o período de estabilidade, o empregado perde o direito a reintegração, podendo apenas ser indenizado com o valor do salário compreendido entre a data da sua dispensa e o fim do período de estabilidade.

A hipótese indenizatória, pode também ser aplicada quando não for razoável determinar a reintegração do trabalhador, visto que, "embora a reintegração no emprego seja medida possível para o combate da discriminação, nem sempre é medida indicada" (OLMOS, 2008, p. 145).

Faz-se importante perceber que a garantia provisória de emprego corre o risco de frustrar sua própria intenção. Isso porque pode incentivar o empregador a não comunicar a ocorrência de determinados acidentes de trabalho, preferindo conceder licença remunerada ao empregado,

com o pagamento dos salários do período em que ele ficou desligado da empresa. (BRASIL, Tribunal Regional do Trabalho do Estado de Goiás, 3a Turma, RO 0002367-73.2011.5.18.0102. Recorrente: Jari Celulose, papel e embalagens S.A., Recorrido: Edcarlos Ferreira de Souza Relator: Paulo Canagé de Freitas Andrade, Julgamento: 27/09/2012, Publicação: 01/10/2012, Disponível em: <www.trt18.jus.br〉. Acesso em 25/10/2018).

${ }^{30}$ BRASIL, Tribunal Superior do Trabalho. Súmula no 396. (...) I - Exaurido o período de estabilidade, são devidos ao empregado apenas os salários do período compreendido entre a data da despedida e o final do período de estabilidade, não lhe sendo assegurada a reintegração no emprego. (...) Disponível em: <http://www3.tst.jus.br/jurisprudencia/Sumulas_com_indiceSumulas_Ind_351_400 .html \#SUM-396>. Acesso em: 04/11/2018 
sem encaminhá-lo ao INSS, para que, posteriormente, ele possa usufruir de sua estabilidade (MARTINEZ, 2003, p. 590).

Ainda, percebe-se que o auxílio-doença acidentário é destinado ao trabalhador que, em decorrência do acidente de trabalho, permanece afastado de sua atividade laboral por período superior a quinze dias ${ }^{31}$. Assim, caso o empregado sofra acidente de trabalho que o incapacite por período de até quinze dias, não terá direito a estabilidade, visto que não irá receber o auxíliodoença acidentário.

A $6^{\text {a }}$ Turma do Tribunal Regional do Trabalho da $9^{\mathrm{a}}$ Região ${ }^{32}$ já expôs esse entendimento ao indeferir pedido de reintegração de reclamante que permaneceu afastado durante cinco dias pós ter sofrido acidente de trabalho. Nesse caso, o entendimento foi no sentido de que, embora tenha restado comprovada a existência de acidente de trabalho, o afastamento que dele decorreu foi inferior a quinze dias, motivo pelo qual o empregado não estaria protegido pela estabilidade acidentária.

Tal entendimento é acertado visto que a norma busca impedir a discriminação em face do trabalhador acidentado que, na maioria das vezes, ocorre porque o empregador sente-se prejudicado pelo longo período em que o empregado permanece afastado em função do infortúnio.

Apesar disso, é possível que o empregado tenha êxito ao pleitear a reintegração a sua função, desde que comprove que sua dispensa foi discriminatória. Ainda, é igualmente possível que o empregado venha a ser indenizado quando ele mesmo tiver pedido a dispensa por estar sofrendo com a prática de atos discriminatório, ou mesmo por ter sido forçado a fazê-lo. Essa circunstância não reflete a real vontade do empregado, por isso, equipara-se a rescisão indireta, passível de indenização (OLMOS, 2008, p. 115).

\footnotetext{
${ }^{31}$ BRASIL, Lei no 8.213, de 24 de Julho de 1991. Dispõe sobre os Planos de Benefícios da Previdência Social e dá outras providências. Diário Oficial da União. Brasília, 25/077/1991. Disponível em: < http://www2.camara.leg.br/legin/fed/lei/1991/lei-8213-24-julho-1991-363650-publicacaooriginal-1-pl.html>. Acesso em: 04/11/2018. Art. 59.

32 - ESTABILIDADE ACIDENTÁRIA - ACIDENTE TÍPICO - AFASTAMENTO NECESSÁRIO INDEFERIMENTO. A garantia de emprego de que cuida o artigo 118 da Lei 8.213/91 tem como requisito o recebimento de auxílio doença acidentário, conforme já se posicionou o C. TST por meio da Súmula 378, II, a seguir transcrita: "II - São pressupostos para a concessão da estabilidade o afastamento superior a 15 dias e a consequente percepção do auxílio-doença acidentário, salvo se constatada, após a despedida, doença profissional que guarde relação de causalidade com a execução do contrato de emprego." No presente caso, a parte reclamante não comprovou o afastamento por período superior a 15 dias e percebimento de auxílio-doença acidentário. Assim, não se encontrava a parte reclamante, quando da rescisão contratual, amparada por estabilidade acidentária prevista no artigo 118 da Lei 8213/91. (BRASIL, Tribunal Regional do Trabalho do Estado do Paraná, 6a Turma, RO 00660-2014-672-09-00-, Recorrente: Marcio Felix, Recorrido: Saratoga Transportes Ltda., Relator: Sérgio Murilo Rodrigues Lemos, Julgamento: 30/08/2017, Publicação: 19/09/2017, Disponível em: <www.trt9.jus.br>. Acesso em 25/10/2018).
} 
Marcus Aurélio Lopes (2002, p. 267), menciona que a justiça deve se atentar ao fato de que, com frequência, os empregados que retornam do afastamento são dispensados pelo empregador, mesmo antes do término do período de estabilidade, o que se comprova pela quantidade de ações de pedido de reintegração decorrentes de estabilidade acidentária que tramitam na Justiça do Trabalho.

Nesse contexto, pode-se entender que para que a garantia de emprego assegurada pelo artigo 118 da Lei 8.213/91 seja eficaz no combate à discriminação do trabalhador acidentado, é necessário que a Justiça do Trabalho adote postura altamente protetiva em relação ao trabalhador vítima de infortúnio laboral.

Tal postura pode ser concretizada por meio da aplicação de multas, por parte do Ministério da Economia ou mesmo da Justiça do Trabalho, em caráter significativo, em função da violação da estabilidade acidentária, que tenha caráter educativo e desestimule o empregador a discriminar o empregado acidentado encerrando seu vínculo empregatício.

\section{CONSIDERAÇÕES FINAIS}

Com a presente pesquisa foi possível compreender que o ordenamento jurídico brasileiro considera como acidente de trabalho aquele que ocorre pelo exercício do trabalho a serviço de empresa, pelo empregado doméstico ou segurado especial, provocando lesão corporal ou perturbação funcional que ocasiona a morte, perda ou redução da capacidade para o trabalho, seja permanente ou temporária. Ou ainda, as doenças ocupacionais, as concausas e outras hipóteses específicas mencionadas em lei.

A partir desse entendimento, verificou-se que o trabalhador acidentado carrega estigma, visto que muitas vezes, ao retornar ao ambiente de trabalho, não pode exercer a mesma função, ou a exerce com produtividade inferior à exercida antes do infortúnio, possibilitando que seja vítima de atos discriminatórios, que podem ocasionar sua rescisão contratual e dificultar sua reinserção no mercado de trabalho.

Buscando reduzir os efeitos de tais atos discriminatórios, a Lei 8.213 de 1991 prevê a concessão de cotas em empresas para pessoas com deficiência habilitadas, e reabilitados pela Previdência Social, e assegura a garantia de emprego pelo período de 12 meses em função de infortúnio laboral.

Com relação às cotas previstas no artigo 93 da referida lei, foi possível concluir que elas só serão eficazes no combate à discriminação do trabalhador acidentado quando o programa de 
reabilitação for verdadeiramente fiscalizado. Isso porque, além de exigir que as empresas contratem o percentual mínimo de trabalhadores, sob pena de multa em valor significante, é necessário certificar-se que os trabalhadores reabilitados estão exercendo apenas funções para as quais estão efetivamente aptos.

Com relação à garantia de emprego, conclui-se que, para que ela seja eficaz no combate à discriminação do trabalhador acidentado, é necessário que a Justiça do Trabalho, ao julgar ações reintegratórias, adote postura simultaneamente protetiva (em relação ao trabalhador vítima de infortúnio laboral), e punitiva (em relação às empresas que não observam a estabilidade provisória em questão).

Contudo, para que tal postura possa ser adota, é necessária a efetiva atuação dos órgãos fiscalizatórios, que possibilitam a atuação do Ministério Público do Trabalho e dos sindicados de categorias profissionais, por meio do ingresso com ações coletivas defendendo o direito dos trabalhadores vítimas de infortúnios laborais. Tal exigência é um verdadeiro desafio no cenário atual, em que as inúmeras reformas legislativas, que buscam a modernização dos contratos de trabalho, demonstram preocupações exacerbadas com a economia das empresas e do Estado, deixando as políticas preventivas em um segundo plano, com grande incerteza e instabilidade.

\section{REFERÊNCIAS BIBLIOGRÁFICAS}

BACILA, Carlos Roberto. Criminologia e Estigmas: Um estudo sobre os preconceitos. 4. ed. São Paulo: Altas, 2015.

BBC NEWS BRASIL. "Estamos presos naquele dia": 1 ano após rompimento de barragem em Brumadinho, os impactos duradouros da tragédia. Disponível em: < https://www.bbc.com/ portuguese/geral-51228582>. Acesso em: 28/03/2020.

BRASIL. Decreto no 3.048, de 06 de maio de 1999. Aprova o Regulamento da Previdência Social, e dá outras providências. Diário Oficial da União, Brasília, DF, 07 de maio de 1999.

BRASIL, Lei $\mathbf{n}^{0}$ 8.213, de 24 de Julho de 1991. Dispõe sobre os Planos de Benefícios da Previdência Social e dá outras providências. Diário Oficial da União. Brasília, 25/07/1991. Disponível em:<http://www2.camara.leg.br/legin/fed/lei/1991/ lei -8213-24-julho-1991363650-publicacaooriginal-1-pl.html $>$. Acesso em: 28/03/2020.

BRASIL, Lei n⿳0 9.504, de 30 de Setembro de 1997. Estabelece normas para as eleições. Diário Oficial da União. Brasília, 1/10/1997. Art. 10, $\$ 3^{\circ}$. Disponível em: <http://www.planalto.gov.br/ ccivil_03/leis/L9504.htm>. Acesso em: 28/03/2020. 
BRASIL, Lei $\mathbf{n}^{\circ}$ 12.711, de 29 de Agosto de 2012. Dispõe sobre o ingresso nas universidades federais e nas instituições federais de ensino técnico de nível médio e dá outras providências. Diário Oficial da União. Brasília, 30/8/2012. Disponível em: <http://www.planalto.gov.br/CCIVIL_03/_ Ato2011-2014/2012/Lei/L12711.htm>. Acesso em: $28 / 03 / 2020$. Art. $1^{\circ}$.

BRASIL. Lei $\mathbf{n}^{\circ} \mathbf{1 3 . 4 6 7}$, de 13 de julho de 2017. Altera a Consolidação das Leis do Trabalho (CLT), aprovada pelo Decreto-Lei $n^{0} 5.452$, de $1^{\circ}$ de maio de 1943 , e as Leis $n^{\text {os }} 6.019$, de 3 de janeiro de 1974, 8.036, de 11 de maio de 1990, e 8.212, de 24 de julho de 1991, a fim de adequar a legislação às novas relações de trabalho. Disponível em <http://www.planalto.gov.br/ccivil_03/_ato2015-2018/2017/lei/L13467 .htm>. Acesso em: 28/03/2020.

BRASIL. Medida Provisória $\mathbf{n}^{\circ}$ 905, de 11 de novembro de 2019. Institui o Contrato de Trabalho Verde e Amarelo, altera a legislação trabalhista, e dá outras providências. Disponível em <http://www.planalto.gov.br/ccivil_03/_Ato2019-2022/2019/Mpv/mpv905.htm\#art51>. Acesso em: 28/03/2020. Art. 51, XIX, b.

CASTRO, Carlos Alberto Pereira de; LAZZARI, João Batista. Manual de direito previdenciário. 11 ed. Florianópolis: Conceito Editorial, 2009.

DELGADO, Maurício Godinho. Curso de Direito do Trabalho. 17. ed. São Paulo: LTr, 2019.

DICIONÁRIO DO AURÉLIO. Disponível em: 〈https://dicionariodoaurelio. com/estigma>. Acesso em: 20/10/2018.

FACHIN, Zulmar. Curso de Direito Constitucional. 7. ed. Rio de Janeiro: Forense, 2015.

FERREIRA, Daniel; GUERIOS, Fernanda Akemi Okazaki. A DISCRIMINAÇÃO DA MULHER PARANAENSE NO MERCADO DE TRABALHO E AS AÇÕES AFIRMATIVAS EM PROL DA IGUALDADE. Revista Juridica, [S.1.], v. 1, n. 46, p. 334-354, jul. 2017. ISSN 2316-753X. Disponível em: <http://revista.unicuritiba.edu.br/index.php/RevJur/article/view/2011/1292>. Acesso em: 20 abr. 2020. doi:http://dx.doi.org/10.21902/revistajur.2316-753X.v1i46.2011.

GOFFMAN, Erving. Estigma: Notas sobre a Manipulação da Identidade Deteriorada. 4. ed. Rio de Janeiro: LTC, 2017.

HORVATH JÚNIOR, Miguel. Direito Previdenciário. 5. ed. São Paulo: Quartier Latin, 2005.

JORGE NETO, Francisco Ferreira; CAVALCANTE, Jouberto de Quadros Pessoa. Direito do trabalho. 6. ed. São Paulo: Atlas, 2012.

LOPES, Marcus Aurélio. Discriminação as relações de trabalho. Dissertação (Mestrado em Direito) - Universidade Estadual de Maringá, Maringá, 2002.

MARTINS, Sério Pinto. Direito da Seguridade Social. 22. ed. São Paulo: Atlas, 2005. 
MARTINEZ, Wladimir Novaes. Comentários à Lei Básica da Previdência Social Wladimir Novaes Martinez. 6. ed. São Paulo: LTr, 2003.

MINISTÉRIO DA ECONOMIA; Secretaria de previdência, Anuário Estatístico de Acidente do Trabalho. Disponível em: < http://www.previdencia.gov.br/dados-abertos/dados-abertossst/>. Acesso em: 28/03/2020.

MINISTÉRIO DA ECONOMIA. Secretaria de previdência. Lei que regulamentou inserção de pessoas com deficiência no mercado de trabalho completa 28 anos. Disponível em $<$ http://www. previdencia.gov.br/noticias/7185-lei-que-regulamentou-insercao -de-pessoascom-deficiencia-no-mercado-de-trabalho-completa-28-anos>. Acesso em 28/03/2020.

OLIVEIRA, Sebastião Geraldo. Indenizações por Acidente de Trabalho ou Doença Ocupacional. 10. ed. São Paulo: LTr, 2018.

OLMOS, Cristina Paranhos. Discriminação da relação de emprego e proteção contra a dispensa discriminatória. São Paulo: LTr, 2008.

TRIBUNAL SUPERIOR DO TRABALHO. Programa Nacional de Prevenção de Acidentes de Trabalho: Acidentes de Trabalho no mundo. Disponível em: <http:// www.tst.jus.br/ web/trabalho seguro/acidentes-de-trabalho-no-mundo>. Acesso em: 28/03/2020.

TRIBUNAL SUPERIOR DO TRABALHO. Súmula $\mathbf{n}^{\mathbf{0}}$ 378. Disponível em: <http://www3.tst.jus.br/jurisprudencia/Sumulas_com_indice/Sumulas_Ind_351_400.

html\#SUM-378>. Acesso em 25/10/2018.

TRIBUNAL SUPERIOR DO TRABALHO. Súmula $\mathbf{n}^{\mathbf{0}}$ 396. Disponível em: $<$ http://www3.tst.jus.br/jurisprudencia/Sumulas_com_indiceSumulas_Ind_351_400 .html\#SUM-396>. Acesso em: 04/11/2018

UOL NOTÍCIAS. Brumadinho é maior acidente de trabalho já registrado no Brasil. Disponível em: <https://noticias.uol.com.br/ultimas-noticias/bbc/2019/01/28/ brumadinhopode-ser-2-maior-desastre-industrial-do-seculo-e-maior-acidente-de-trabalho-do-brasil.html > Acesso em: 01/03/2019.

VICENTINO, Cláudio; DORIGO, Gianpaolo. História Geral e do Brasil. 1. ed. São Paulo: Scipione, 2010. p.398. 